\title{
Pemilihan Kebutuhan Unsur Hara Dengan Metode Certainty Factor Pada Tanaman Dalam Pot (Tabulampot)
}

\author{
Muntahanah $^{1}$, Sri Handayani ${ }^{2}$, Oktarani Nurlestari ${ }^{3}$, Jefri Alexander ${ }^{4}$ \\ 1,2,3 Program Studi Teknik Informatika Universitas Muhammadiyah Bengkulu \\ ${ }^{4}$ Program Studi Sistem Informasi Universitas Muhammadiyah Bengkulu \\ Jln. Bali Kota Bengkulu 38119
}

\begin{abstract}
As the population increases rapidly, it can not be avoided the reduction of land in the surrounding environment. This, can affect the desire of the community to apply a hobby or the desire to grow crops due to land limitations. However, it allows the influence of other factors, for example fond of caring for plants but less interested in the usual planting media, where the elements needed by plants for the process of plant growth, then the levels of nutrients in the soil determine the fertility of the soil planting in potting media can be one of the innovations that are easily carried out by the community, planting in pots is also a way to anticipate land limitations and plant growth depending on the amount of nutrients supplied to the plant media Usually nutrients contained in the planting medium is incomplete and cannot meet the needs of the whole plant, then a system is built that can help solve the problem using the Certainty Factor $(C F)$ method in which the exact and uncertain determination is in the form of a matrix. Test results Based on the results of user-tested systems, spinach has a $\mathrm{Cf}$ of $90.4 \%$, chili has a $\mathrm{Cf}$ of $89.6 \%$, potatoes have a $\mathrm{Cf}$ of $90.5 \%$, brown must have a Cf of $89.6 \%$, tomatoes have a Cf amounted to $63.6 \%$ and weaknesses if the data is more than two, the data processing must be repeated repeatedly.
\end{abstract}

Abstrak - Seiring peningkatan jumlah penduduk yang semakin pesat maka tidak dapat dihindari pengurangan lahan pada lingkungan sekitar. Hal ini, dapat mempengaruhi keinginan masyarakat untuk mengaplikasikan hobi ataupun keinginan untuk bercocok tanam dikarenakan Keterbatasan lahan, namun, memungkinkan ada pengaruh faktor lain, misalkan gemar memelihara tanaman namun kurang tertarik dengan media tanam yang biasa, dimana unsur yang diperlukan tanaman untuk proses pertumbuhan tanaman, maka kadar unsur hara dalam tanah menentukan kesuburan tanah menanam dalam media pot dapat menjadi salah satu inovasi yang gampang dilakukan masyarakat, menanam dalam pot juga salah satu cara untuk mensiasati keterbatasan lahan dan pertumbuhan tanaman tergantung banyaknya unsur hara yang diberikan pada media tanaman Biasanya unsur hara terdapat di dalam media tanam tidaklah lengkap dan tidak dapat memenuhi kebutuhan tanaman keseluruhan maka dibangun sesuatu sistem yang dapat membantu menyelesaikan permasalah dengan menggunakan metode Certainty Factor (CF) dimana pentuan pasti dan tidak pastinya berbentuk matrik . Hasil pengujian Berdasarkan hasil dari pengujian sistem yang dilakukan user, bayam memiliki Cf sebesar 90,4\%, cabai memiliki Cf sebesar 89,6\%, kentang memiliki Cf sebesar 90,5\%, sawo memiliki Cf sebesar 89,6\%, tomat memiliki Cf sebesar 63,6\% dan kelemahan kalau datanya lebih dari dua maka proses pengolahan data harus dilakukan berualang kali.

Keywords - tanaman, tabulan pot, unsur hara, certainty factor

\section{Pendahuluan}

Seiring peningkatan jumlah penduduk yang semakin pesat maka tidak dapat dihindari pengurangan lahan pada lingkungan sekitar.Hal ini, dapat mempengaruhi keinginan masyarakat untuk mengaplikasikan hobi ataupun keinginan untuk bercocok tanam dikarenakan Keterbatasan lahan.Namun, memungkinkan ada pengaruh faktor lain, misalkan ingin memiliki lahan tanaman namun kurang tertarik dengan media tanam yang biasa. Menanam dalam media pot dapat menjadi salah satu inovasi yang mudah dilakukan masyarakat, menanam dalam pot juga salah satu cara untuk mensiasati keterbatasan lahan, bertanam dengan cara ini memungkinkan masyarakat juga membutuhkan pengetahuan khusus dalam pemilihan tanah ataupun hal-hal yang lain yang dibutuhkan tanaman dalam pot. Pada umumnya sudah ada yang mencoba bercocok tanam dalam media pot namun belum mengetahui apa saja yang mempengaruhi tanaman tersebut agar dapat tumbuh dengan bagus. Salah satunya yaitu unsur tanaman itu sendiri, banyak masyarakat yang menanam dalam pot namun hanya sebatas tanah yang diletakkan dalam pot lalu langsung ditanam tanpa diperhatikan apa saja yang diperlukan oleh tanaman tersebut.

Unsur yang dibutuhkan tanaman untuk proses pertumbuhan tanamanadalah unsur hara, oleh karena itu, kadar unsur hara dalam tanah menentukan fertiitas tanah. Secara umum dapat dikatakan bahwa semakin tinggi kadar unsur hara (sampai batas tertentu), semakin tinggi kesuburan tanahnya ${ }^{1}$. Metode yang mendefinisikan ukuran kapasitas terhadap suatu fakta atau aturan, dalam mengekspresikan tingkat keyakinan seorang pakar terhadap suatu masalah adalah Certainty Factor (CF) memperkenalkan konsep belief atau keyakinan dan disbelife atau ketidakyakinan, suatu metode untuk membuktikan apakah suatu fakta itu nyata ataukah 
tidak dalam bentuk ${ }^{2}$.Pengembangan dalam konteks pertanian, merupakan kegiatan terencana pemeliharaan sumber daya hayati yang dilakukan pada suatu area lahan untuk diambil manfaat/hasil panennya. Usaha pengembangan tanaman mengandalkan penggunaan tanah atau media lainnya disuatu lahan untuk membesarkan tanaman dan memeliharanya agar bisa memanen varitas yang bernilai ekonomi ${ }^{3}$.

\section{Landasan Teori}

A. Unsur Hara

Kebutuhan unsur hara pada tanaman dibagi menjadi dua golongan, yakni unsur hara makro dan unsur hara mikro, dimana unsur makro diperlukan diperlukan tanaman dalam jumlah lebih banyak dibandingkan dengan unsur mikro ${ }^{4}$. Setiap tanaman baik tanaman tahunan ataupun tanaman musiman pasti memerlukan unsur hara untuk tumbuh dan berkembang serta untuk mendapatkan hasil. Dalam kenyataannya unsur hara tersebut dapat diperoleh secara in situ (langsung dari dalam tanah) maupun dari luar berupa input produksi ${ }^{5}$.

Pertumbuhan tanaman tergantung banyaknya unsur hara yang diberikan pada media tanaman, umumnya unsur hara terdapat di dalam media tanam tidaklah komplit untuk kebutuhannya ${ }^{6}$.

\section{B. Metode Certainty Factor}

Certainty factor adalah suatu metode untuk membuktikan apakah suatu fakta itu pasti ataukah tidak pasti yang berbentuk metric yang biasanya digunakan dalam sistem pakar. Metode ini sangat cocok untuk sistem pakar yang mendiagnosis sesuatu yang belum pasti ${ }^{7}$.

\section{Tabulan Pot}

Tabulampot sebenarnya bukan hal yang baru lagi tetapi sudah lama ini dilakukan oleh banyak orang, istilah tabulampot merupakan singkatan dari tanaman buah dalam pot $^{8}$. Pertumbuhan dan perkembangan tanaman sangat dipengaruhi oleh pemberian pupuk dan ketersediaan unsur di media tanahnya, untuk mencapai pertumbuhan optimal, seluruh unsur hara harus sebanding tidak boleh kurang atau berlebihan ${ }^{9}$. Pupuk anorganik proanalisis merupakan pupuk kimia buatan yang mempunyai tingkat kemurnian hampir $100 \%$. Chlorella SPdapat tumbuh dalam berbagai media yang mengandung cukup unsur hara, seperti N, P, $\mathrm{K}$ dan unsur mikro lainnya. pada temperatur optimal $25^{\circ} \mathrm{C}$. unsur yang diperlukan mikroalga dalam jumlah besar adalah karbon, nitrogen, fosfor, sulfur, natrium, magnesium dan kalsium. (Z). Sedangkan unsur hara yang dibutuhkan dalam jumlah relatif sedikit adalah besi (Fe), tembaga $(\mathrm{Cu})$, mangan $(\mathrm{Mn})$, seng $(\mathrm{Zn})$, silicon ( $\mathrm{Si})$, boron (B), molibdenum (Mo), vanadium (V) dan kobalt (Co)
[10]. Hal-hal yang mempengaruhi proses adalah respirasi, konsentrasi, kerapatan dan penyebaran dan daya serap akar dan $\mathrm{PH} \operatorname{tanah}^{11}$. Bakteri ini berfungssi menambatkan $\mathrm{N}$ dari udara dan memacu pertumbuhan tanaman dan zat yang dihasilkanadalah gibberellins, cytokinins dan idolacetic $^{12}$. Bahan organik tanah merupakan suatu sistem yang komplek dan dinamis, berasal dari sisa tanaman juga hewan yang terdapat di dalam tanah yang mengalami perubahan karena dipengaruhi faktor biologi, fisika dan kimia yang ada didalam $\operatorname{tanah}^{13}$.

\section{Metode Penelitian}

\section{A. Tempat Penelitian}

Riset dilaksanakan di Dinas Pangan dan Pertanian Kota Bengkulu , Jalan Irian Km. 6,5 Bengkulu

\section{B. Metode Pengumpulan Data}

\section{Metode Interview}

Wawancara dilakukan dengan pegawai Dinas Pangan dan Pertanian Kota Bengkulu yang membidangi tanaman palawija dan tanaman keras

2. Metode observasi

Melihat secara langsung proses pengembangan tanaman yang ada di Dinas Pangan dan Pertanian Kota Bengkulu di tempat pengembangan tanaman palawija dan tanaman keras

3. Metode kepustakaan

Memcari referensi yang baku baik itu di perpustakaan, di dinas dan juga browsing di internet sebagai pelengkap dlam pembuatan sistem yang dibutuhkan

\section{Metode Pengembangan Sistem}

Proses pengembangan sistem seringkali menggunakan pendekatan prototipe (prototyping). Metode ini sangat baik digunakan untuk menyelesesaikan masalah kesalahpahaman antara user dan analis yang timbul akibat user tidak mampu mendefinisikan secara jelas kebutuhannya, dimualai dari indentifikasi kebutuhan, pengembangan sitem, proses perbaikan/revisi system yang dibuat dan proses perawatan system yang ada. 
a. Flowchart

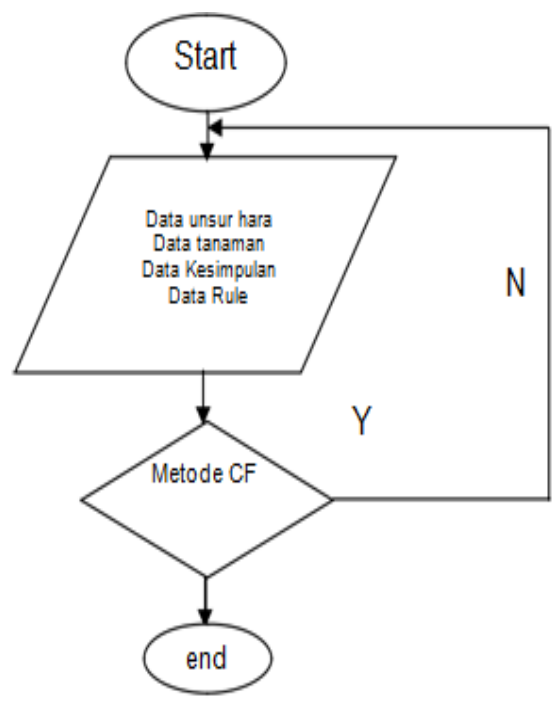

Gbr 1. Flowchart

b. Analisis Manual

Analisis manual untuk penentuan unsur hara ini adalah mengidentifikasi unsur hara pada setiap tanaman. kemudian dirancang sebuah sistem pakar yang dapat menentukan unsur yang dibutuhkan tanaman dalam pot, Berikut rincian tanamanyang menjadi kebutuhanpada setiap tanaman :

1. Nama Tanaman

Adapun Klasifikasi tanaman terlihat pada tabel berikut:

Tabel 1. Nama tanaman

\begin{tabular}{cl}
\hline $\begin{array}{c}\text { Kode } \\
\text { Tanaman }\end{array}$ & \multicolumn{1}{c}{ Nama Tanaman } \\
\hline T1 & Bayam \\
T2 & Cabai \\
T3 & Kentang \\
T4 & Sawo \\
T5 & Tomat \\
\hline
\end{tabular}

2. Unsur Hara

Adapun unsur hara yang akan dibutuhkan tanaman terlihat pada tabel berikut:

Tabel 2. Unsur Hara

\begin{tabular}{cc}
\hline Kode unsur hara & Nama unsur hara \\
\hline H1 & $\mathrm{Fe}$ \\
$\mathrm{H} 2$ & $\mathrm{Mn}$ \\
$\mathrm{H} 3$ & $\mathrm{Cu}$ \\
$\mathrm{H} 4$ & $\mathrm{Zn}$ \\
$\mathrm{H} 5$ & $\mathrm{~B}$ \\
H6 & Mo \\
\hline
\end{tabular}

\section{Rule}

Adapun rule sistem pakar kebutuhan unsur hara dapat dilihat pada tabel berikut:

Tabel 3. Rule

\begin{tabular}{|c|c|c|c|}
\hline $\begin{array}{l}\text { Kode } \\
\text { Rule }\end{array}$ & $\begin{array}{c}\text { Kode } \\
\text { Tanaman }\end{array}$ & $\begin{array}{l}\text { Kode } \\
\text { Unsur } \\
\text { Hara }\end{array}$ & $\begin{array}{l}\text { Kode } \\
\text { Kesim } \\
\text { pulan }\end{array}$ \\
\hline \multirow[t]{6}{*}{$\mathrm{R} 1$} & $\mathrm{~T} 1$ & H1 & K1 \\
\hline & & $\mathrm{H} 2$ & $\mathrm{~K} 2$ \\
\hline & & H3 & K3 \\
\hline & & $\mathrm{H} 4$ & K4 \\
\hline & & H5 & K5 \\
\hline & & H6 & K6 \\
\hline \multirow[t]{6}{*}{$\mathrm{R} 2$} & $\mathrm{~T} 2$ & H1 & K1 \\
\hline & & $\mathrm{H} 2$ & $\mathrm{~K} 2$ \\
\hline & & $\mathrm{H} 3$ & K3 \\
\hline & & $\mathrm{H} 4$ & K4 \\
\hline & & H5 & K5 \\
\hline & & H6 & K6 \\
\hline \multirow[t]{6}{*}{ R3 } & T3 & H1 & $\mathrm{K} 1$ \\
\hline & & $\mathrm{H} 2$ & $\mathrm{~K} 2$ \\
\hline & & H3 & K3 \\
\hline & & $\mathrm{H} 4$ & K4 \\
\hline & & H5 & K5 \\
\hline & & H6 & K6 \\
\hline \multirow[t]{6}{*}{$\mathrm{R} 4$} & $\mathrm{~T} 4$ & $\mathrm{H} 1$ & $\mathrm{~K} 1$ \\
\hline & & $\mathrm{H} 2$ & $\mathrm{~K} 2$ \\
\hline & & H3 & K3 \\
\hline & & $\mathrm{H} 4$ & K4 \\
\hline & & H5 & K5 \\
\hline & & H6 & K6 \\
\hline \multirow[t]{6}{*}{ R5 } & T5 & H1 & K1 \\
\hline & & $\mathrm{H} 2$ & $\mathrm{~K} 2$ \\
\hline & & H3 & K3 \\
\hline & & $\mathrm{H} 4$ & $\mathrm{~K} 4$ \\
\hline & & H5 & K5 \\
\hline & & H6 & K6 \\
\hline
\end{tabular}

4. Pembobotan

Tabel 4. Pembobotan

\begin{tabular}{|c|c|c|c|c|c|c|}
\hline & \multicolumn{6}{|c|}{$\begin{array}{l}\text { Unsur Hara } \\
\text { Mikro }\end{array}$} \\
\hline & & $\mathrm{M}$ & & & & \\
\hline & $\mathrm{Fe}$ & $\mathrm{n}$ & $\mathrm{Cu}$ & $\mathrm{Zn}$ & B & Mo \\
\hline \multicolumn{7}{|c|}{ Baya } \\
\hline Nilai MB & 0,9 & 0,9 & 0,8 & 0,9 & 0,9 & 0,9 \\
\hline Nilai MD & 0,2 & 0,3 & 0,2 & 0,3 & 0,2 & 2 \\
\hline $\begin{array}{l}\text { Kebutuha } \\
\mathrm{n}(\%)\end{array}$ & 30 & 25 & 30 & 30 & 25 & 30 \\
\hline \multicolumn{7}{|c|}{ Cabai } \\
\hline Nilai MB & 0,9 & 0,8 & 0,9 & 0,9 & 0,8 & $\begin{array}{r}0,8 \\
0,\end{array}$ \\
\hline Nilai MD & 0,3 & 0,2 & 0,3 & 0,2 & 0,2 & 3 \\
\hline
\end{tabular}

48 |http://www.jurnal.umb.ac.id/index.php/JTIS 
Kebutuha

\begin{tabular}{|c|c|c|c|c|c|c|}
\hline $\mathrm{n}(\%)$ & 30 & 25 & 30 & 30 & 25 & 30 \\
\hline \multicolumn{7}{|c|}{ Kentang } \\
\hline Nilai MB & 0,8 & 0,9 & 0,9 & 0,8 & 0,9 & 0,9 \\
\hline Nilai MD & 0,2 & 0,2 & 0,3 & 0,2 & 0,2 & $\begin{array}{l}0, \\
3\end{array}$ \\
\hline Kebutuha & & & & & & \\
\hline $\mathrm{n}(\%)$ & 25 & 15 & 30 & 20 & 20 & 20 \\
\hline \multicolumn{7}{|c|}{ Sawo } \\
\hline Nilai MB & 0,8 & 0,9 & 0,8 & 0,9 & 0,9 & $\begin{array}{l}0, \\
9\end{array}$ \\
\hline Nilai MD & 0,2 & 0,3 & 0,2 & 0,2 & 0,3 & 3 \\
\hline $\begin{array}{l}\text { Kebutuha } \\
\mathrm{n}(\%)\end{array}$ & 30 & 20 & 30 & 30 & 25 & 30 \\
\hline \multicolumn{7}{|c|}{$\begin{array}{l}\text { Tom } \\
\text { at }\end{array}$} \\
\hline Nilai MB & 0,9 & 0,8 & 0,8 & 0,9 & 0,8 & 0,9 \\
\hline Nilai MD & 0,3 & 0,2 & 0,2 & 0,3 & 0,2 & 0,3 \\
\hline $\begin{array}{l}\text { Kebutuha } \\
\mathrm{n}(\%)\end{array}$ & 30 & 25 & 30 & 30 & 25 & 30 \\
\hline
\end{tabular}

Berikut ini merupakan salah satu contoh pembahasan menggunakan metode Certainty Factor tentang pengetahuan dasar dan informasi mengenai unsur hara pada tanaman cabai. Dengan rule sebagai berikut :

Pada sesi konsultasi sistem user diberi jawaban yang masing -masing memiliki bobot sebagai berikut:

1. Untuk dua pilihan jawaban: Tidak $=0 ; \mathrm{Ya}=1$

2. Untuk lima pilihan jawaban: Tidak $=0$; Sedikit yakin $=0,4 ;$ Cukup yakin $=0,6 ; \quad$ Yakin $=0,8$; Sangat yakin

\begin{tabular}{|l|l|}
\hline $\begin{array}{l}\mathrm{CF}[\mathrm{H}, \mathrm{E}] 1=\mathrm{cf}[\mathrm{H}] \mathrm{ke}- \\
1 * \mathrm{CF}[\mathrm{E}] \mathrm{ke}-1\end{array}$ & $\begin{array}{l}0,9 * 0,3 \text { sama } \\
\text { dengan } 0,27\end{array}$ \\
\hline $\mathrm{CF}[\mathrm{H}, \mathrm{E}] 2=\mathrm{cf}[\mathrm{H}] \mathrm{ke}-$ & $0,8 * 0,2$ sama \\
$2 * \mathrm{CF}[\mathrm{E}] \mathrm{ke}-2$ & dengan 0,16 \\
\hline $\mathrm{CF}[\mathrm{H}, \mathrm{E}] 3=\mathrm{cf}[\mathrm{H}] \mathrm{ke}-$ & $0,9 * 0,3$ sama \\
$3 * \mathrm{CF}[\mathrm{E}] \mathrm{ke}-3$ & dengan 0,27 \\
\hline $\mathrm{CF}[\mathrm{H}, \mathrm{E}] 4=\mathrm{cf}[\mathrm{H}] \mathrm{ke}-$ & $0,9 * 0,2 \mathrm{sama}$ \\
$4 * \mathrm{CF}[\mathrm{E}] \mathrm{ke}-4$ & dengan 0,18 \\
\hline $\mathrm{CF}[\mathrm{H}, \mathrm{E}] 5=\mathrm{cf}[\mathrm{H}] \mathrm{ke}-$ & $0,8 * 0,2 \mathrm{sama}$ \\
$5 * \mathrm{CF}[\mathrm{E}] \mathrm{ke}-5$ & dengan 0,16 \\
\hline $\mathrm{CF}[\mathrm{H}, \mathrm{E}] 6=\mathrm{cf}[\mathrm{H}] \mathrm{ke}-$ & $0,8 * 0,3$ sama \\
$6 * \mathrm{CF}[\mathrm{E}] \mathrm{ke}-6$ & dengan 0,24 \\
\hline
\end{tabular}

Step awal adalah menentukan CF untuk setiap unsur hara yang telah ditentukan sebagai berikut: CFcombine $\mathrm{CF}[\mathrm{H}, \mathrm{E}] 1,2=\mathrm{CF}[\mathrm{H}, \mathrm{E}] 1+\mathrm{CF}[\mathrm{H}, \mathrm{E}] 2$ * $(1-\mathrm{CF}[\mathrm{H}, \mathrm{E}] 1)=0,27+0,16 *(1-0,27)=0,389$ old CFcombine $\mathrm{CF}[\mathrm{H}, \mathrm{E}]$ old, $3=\mathrm{CF}[\mathrm{H}, \mathrm{E}]$ old + $\mathrm{CF}[\mathrm{H}, \mathrm{E}] 3 *(1-\mathrm{CF}[\mathrm{H}, \mathrm{E}] \mathrm{old})=0,389+0,27 *(1-$ $0,389)=0,576$ old 2

CFcombine $\mathrm{CF}[\mathrm{H}, \mathrm{E}] 2,4=\mathrm{CF}[\mathrm{H}, \mathrm{E}] \mathrm{old} 2+$ $\mathrm{CF}[\mathrm{H}, \mathrm{E}] 4 *(1-\mathrm{CF}[\mathrm{H}, \mathrm{E}] \mathrm{old} 2)=0,576+0,18 *(1-$ $0,578)=0,689$ old 3
CFcombine $\mathrm{CF}[\mathrm{H}, \mathrm{E}] \mathrm{old} 3,5=\mathrm{CF}[\mathrm{H}, \mathrm{E}]$ old $3+$ $\mathrm{CF}[\mathrm{H}, \mathrm{E}] 5 *(1-\mathrm{CF}[\mathrm{H}, \mathrm{E}] \mathrm{old} 3)=0,689+0,16 *(1-$ $0,689)=0,768$ old 4

CFcombine $\mathrm{CF}[\mathrm{H}, \mathrm{E}] \mathrm{old} 4,5=\mathrm{CF}[\mathrm{H}, \mathrm{E}]$ old $4+$ $\mathrm{CF}[\mathrm{H}, \mathrm{E}] 5 *(1-\mathrm{CF}[\mathrm{H}, \mathrm{E}] \mathrm{old} 4)=0,768+0,24 *(1-$ $0,768)=0,896$ old 5

Cf $[\mathrm{H}, \mathrm{E}] \mathrm{old} 5 * 100 \%=0,896 * 100 \%=89,6 \%$

Dengan demikian dapat dikatakan bahwa perhitungan certainty factor kebutuhan unsur hara pada tanaman cabai memiliki presentase tingkat keyakinan $89,6 \%$

\section{Hasil dan Pembahasan}

A. Hasil

1. Menu

Menu utama merupakan menu yang berisi tutorial cara a membuka sistem dan pada menu utama terdiri dari sekilas info tentang unsur hara, menu Beranda dan Pilihan Login dan Tampilan Menu Unsur Hara

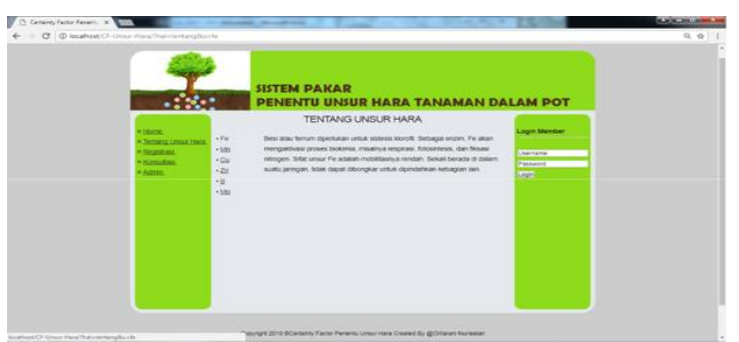

Gambar 2. Menu Unsur Hara

2. Tampilan Menu Input Data Member dan Menu Login Member

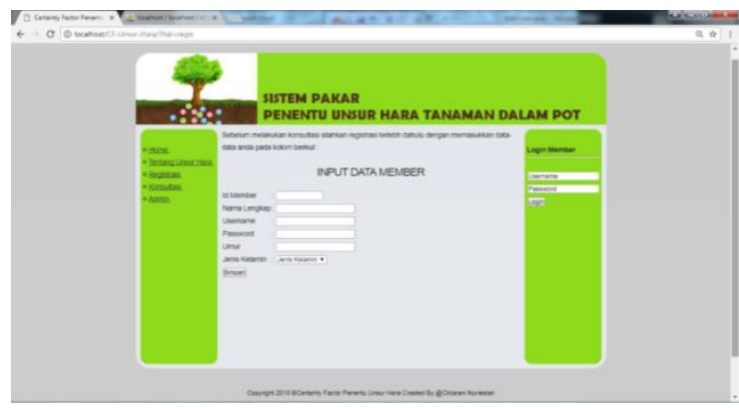

Gambar 3. Menu Input Data Member

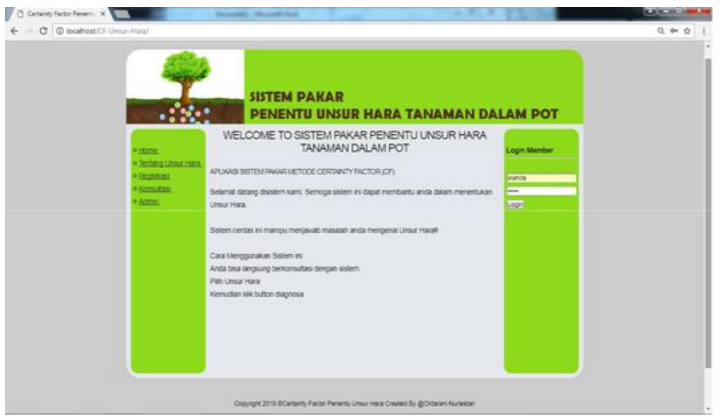

Gambar 4. Menu Login Member 
3. Tampilan Menu Konsultasi dan Menu Form Konsultasi

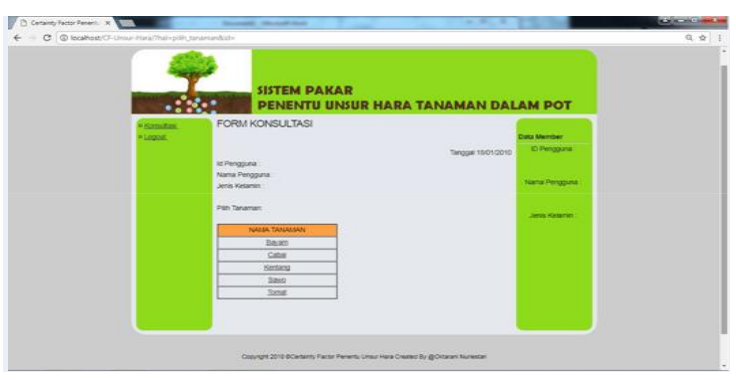

Gambar 5. Tampilan Konsultasi

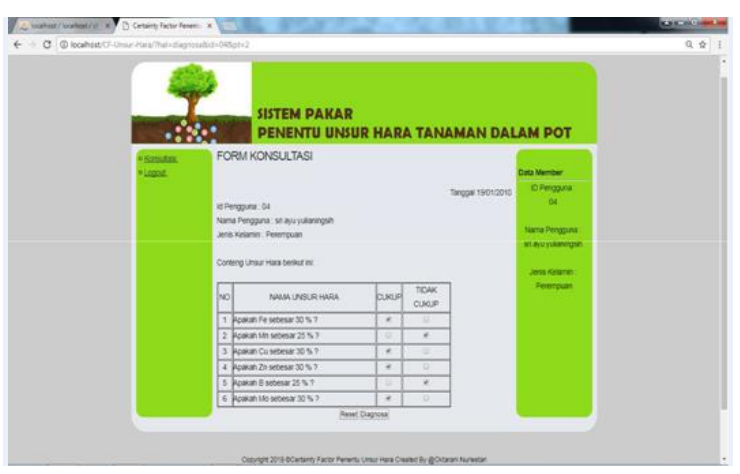

Gambar 6. Tampilan Form Konsultasi

4. Tampilan Menu Hsil Konsultasi dan Menu Cetak Hasil

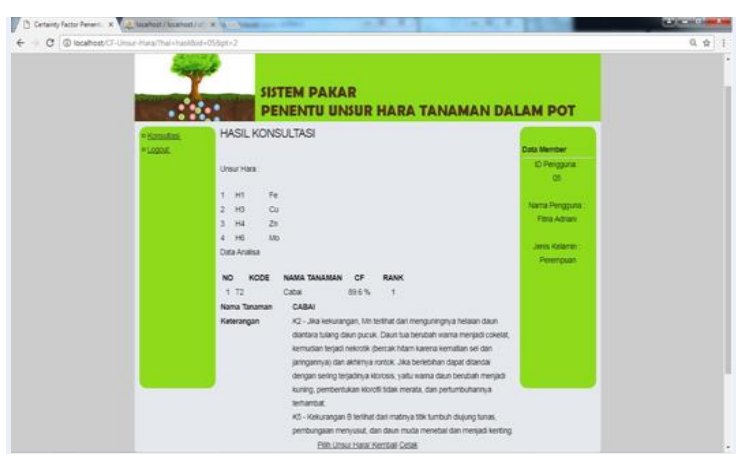

Gambar 7. Menu Hasil Konsultasi

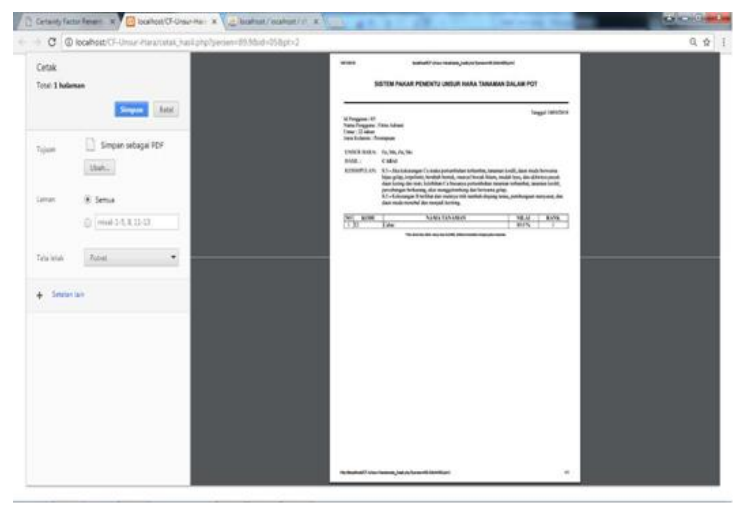

Gambar 8. Menu Cetak Hasil
5. Tampilan Menu Unsur Hara dan Tampilan Data Tanaman

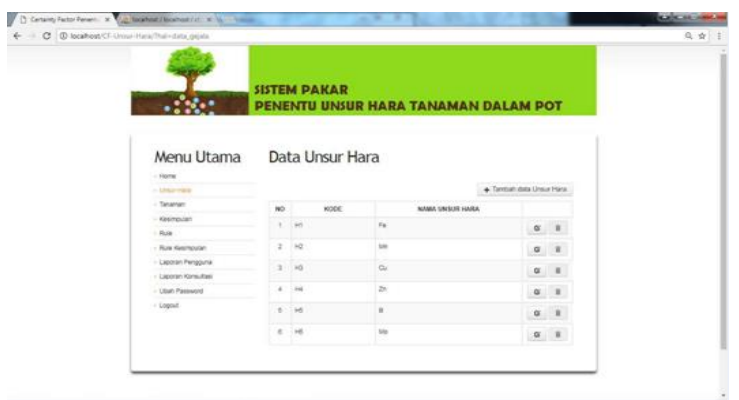

Gambar 9. Tampilan Menu Unsur Hara

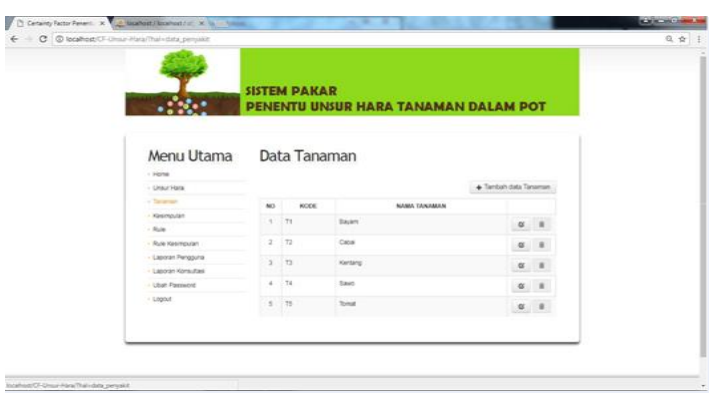

Gambar 10. Tampilan Data Tanaman

6. Tampilan Olah Data Kesimpulan dan Tampilan Laporan Data Pengguna

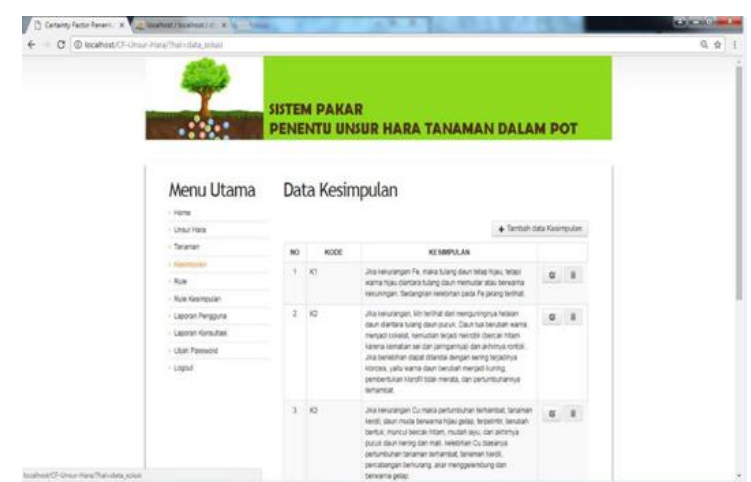

Gambar 11. Tampilan Olah Kesimpulan

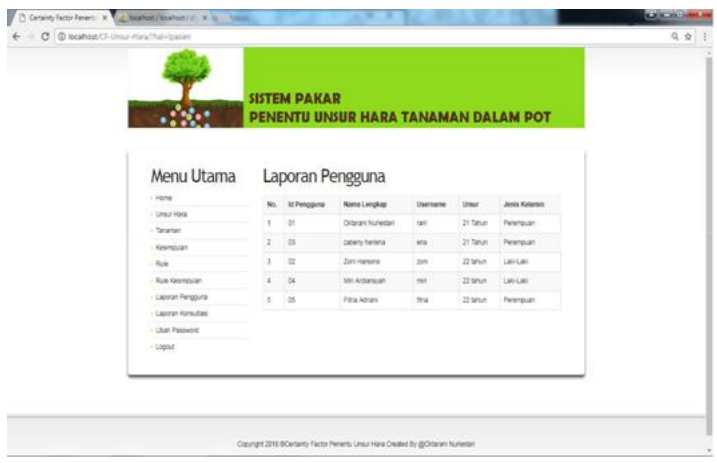

Gambar 12. Tampilan Data Pengguna 
7. Tampilan Data Laporan Konsultasi dan Tampilan Ubah Password

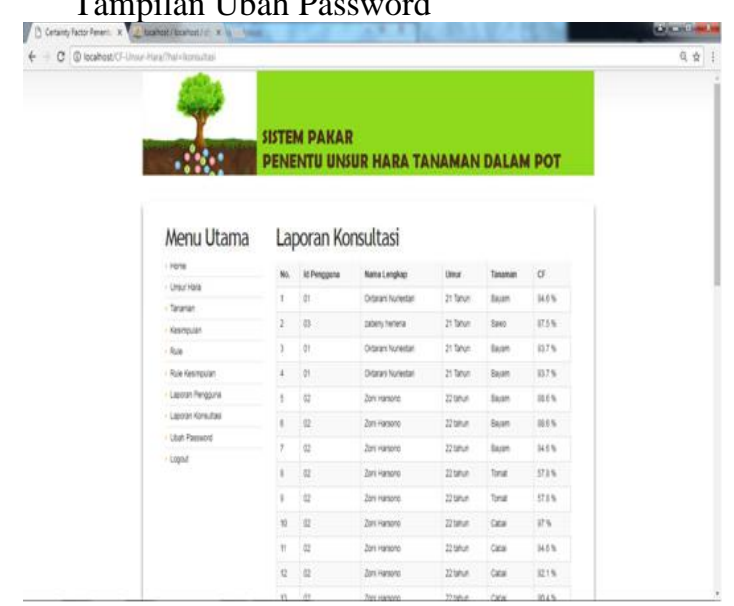

Gambar 13. Tampilan Data Konsultasi

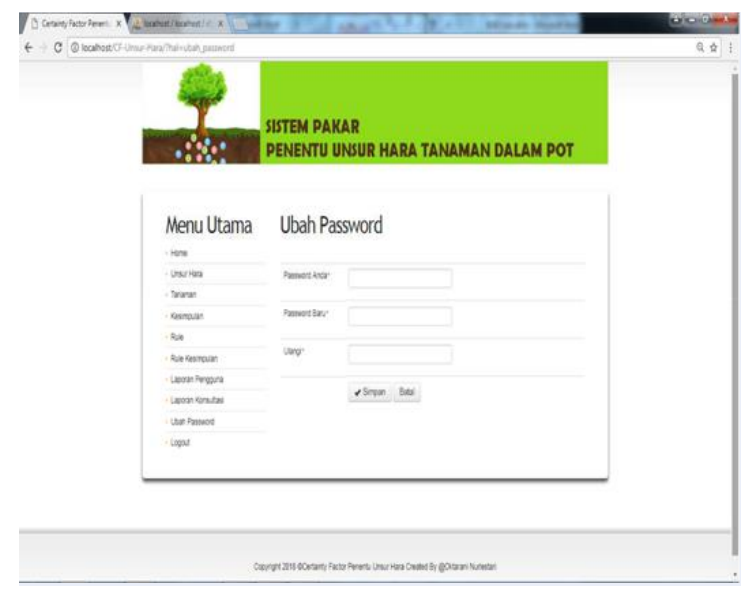

Gambar 14. Tampilan Ubah Password

\section{B. Pembahasan}

Berikut hasil pengujian Penentu Unsur Hara Tanaman Dalam Pot

Tabel 5. Pengujian

\begin{tabular}{llll}
\hline No & Pengujian & $\begin{array}{c}\text { Tanaman } \\
\text { Yang di } \\
\text { Uji }\end{array}$ & Nilai CF \\
\hline 1 & $\begin{array}{l}\text { Uji coba } \\
\text { ke } 1\end{array}$ & Bayam & $90,40 \%$ \\
2 & $\begin{array}{l}\text { Uji coba } \\
\text { ke 2 }\end{array}$ & Kentang & $90,50 \%$ \\
3 & $\begin{array}{l}\text { Uji coba } \\
\text { ke 3 }\end{array}$ & Cabai & $89,60 \%$ \\
4 & $\begin{array}{l}\text { Uji coba } \\
\text { ke } 4\end{array}$ & Sawo & $89,60 \%$ \\
5 & $\begin{array}{l}\text { Uji coba } \\
\text { ke 5 }\end{array}$ & Tomat & $63,60 \%$ \\
\hline
\end{tabular}

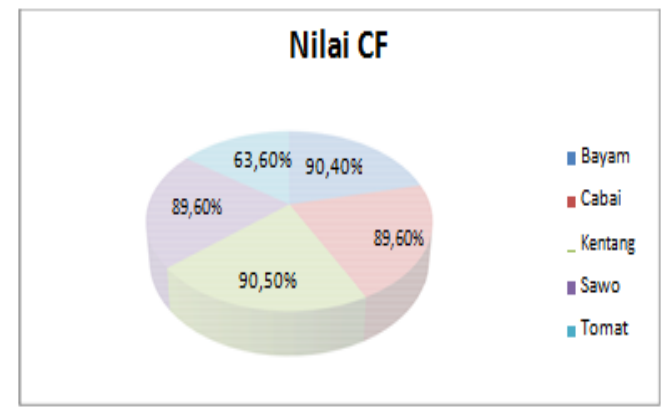

Gambar 15. Hasil Pengujian

Adapun hasil pengujian pada setiap unsur hara dapat dilihat pada table berikut :

\begin{tabular}{|c|c|c|}
\hline $\begin{array}{l}\text { Nama } \\
\text { Unsur } \\
\text { Hara }\end{array}$ & $\begin{array}{l}\text { Kode } \\
\text { Kesim } \\
\text { pulan }\end{array}$ & Kesimpulan \\
\hline $\mathrm{Fe}$ & K1 & $\begin{array}{l}\text { Jika kekurangan Fe, maka tulang daun } \\
\text { tetap hijau tetapi warna hijau diantara } \\
\text { tulang daun memudar atau berwarna } \\
\text { kekuningan. Sedangkan kelebihan } \\
\text { pada Fe jarang terlihat }\end{array}$ \\
\hline $\mathrm{Mn}$ & $\mathrm{K} 2$ & $\begin{array}{l}\text { Jika kekurangan, Mn terlihat dari } \\
\text { menguningnya helaian daun diantara } \\
\text { tulang daun pucuk, daun tua berubah } \\
\text { warna menjadi cokelat lalu terjadi } \\
\text { nekrotik (bercak hitam karena } \\
\text { kematian sel dan jaringannya) dan } \\
\text { akhirnya rontok. Kalau berlebihan } \\
\text { dapat ditandai dengan sering terjadinya } \\
\text { klorosis, yaitu warna daun berubah } \\
\text { menjadi kekuningan, pembentukan } \\
\text { zat hijua daun tidak merata, dan } \\
\text { pertumbuhannya melambat. }\end{array}$ \\
\hline $\mathrm{Cu}$ & $\mathrm{K} 3$ & $\begin{array}{l}\text { Jika CUnya kekurang maka } \\
\text { pertumbuhan melambat, tanaman } \\
\text { kerdil, daun muda berwarna gelao } \\
\text { hijau gelap, bentuknya terjadi } \\
\text { perubahan, bercak hitam, menjadi } \\
\text { layuh, akibatnya daun paling atas } \\
\text { kering dan mati. Cu yang berlebihan } \\
\text { biasanya pertumbuhan tanaman } \\
\text { melambat, tanaman menjadi kerdil, } \\
\text { percabangan berkurang, akar } \\
\text { membengkak dan berwarna kelam. }\end{array}$ \\
\hline $\mathrm{Zn}$ & $\mathrm{K} 4$ & $\begin{array}{l}\text { Jika kekurangan terlihat dari } \\
\text { memendeknya jarak antara ruas } \\
\text { batang, ukuran daun menciut, } \\
\text { pimggir daun sering bergelombang } \\
\text { dan adakalanya terjadi perubahan } \\
\text { warna yang menjadi kuning diantara } \\
\text { tulang daun. Kelebihan Zn terlihat dari } \\
\text { terjadinya perubahan warna yang } \\
\text { menjadi kuning. }\end{array}$ \\
\hline B & K5 & $\begin{array}{l}\text { Kekurangan B terlihat dari matinya } \\
\text { titik tumbuh muda menebal dan } \\
\text { menjadi keriting }\end{array}$ \\
\hline Mo & K6 & $\begin{array}{l}\text { Jika kekurangan terlihat dari } \\
\text { menguningnya helaian antartulang } \\
\text { daun, dimulai dari daun tua yang } \\
\text { terletak dibawah ke daun yang terletak } \\
\text { di atasnya. Kadang-kadang daun } \\
\text { melengkung dan tepinya hangus. Pada } \\
\text { tanaman tomat kelebihan Mo berupa } \\
\text { daun berwarna kuning keemasan }\end{array}$ \\
\hline
\end{tabular}




\section{Kesimpulan}

Berdasarkan hasil dari pengujian sistem yang dilakukan user, bayam memiliki cf sebesar 90,4\%, cabai memiliki cf sebesar $89,6 \%$, kentang memiliki CF sebesar 90,5\%, sawo memiliki CFsebesar 89,6\%, tomat memiliki CF sebesar 63,6\%, kelebihan dari $\mathrm{CF}$ ini sekali proses dua data sekaligus, keakuratnya dapat terjaga dan metode ini mempunyai kelemahan kalau datanya lebih dari dua maka proses pengolahan data harus dilakukan berulang kali.

\section{Referensi}

[1] Utomo Muhajir, dkk, 2016, Ilmu Tanah, Prenadamedia Group, Jakarta

[2] Sihotang, H. T. (2017). Sistem Pakar Mendiagnosa Penyakit Kolesterol Pada Remaja Dengan Metode Certainty Factor (Cf) Berbasis Web. Jurnal Mantik Penusa, 15(1).

[3] Widyawati Nugraheni, 2015, Cara Mudah Bertanam 29 Jenis Sayur Dalam Pot, C.V Andi Offset, Yogyakarta

[4] Rosmarkam Afandie \& Yuwono N. W, 2002, Ilmu

[5] Budianta, D. (2013). Pengelolaan Kesuburan Tanah Mendukung Pelestarian Sumberdaya Lahan dan Lingkungan.

[6] Syapri, S. (2018). Pengaruh Pemberian Unsur Hara Terhadap Pertumbuhan Tanaman Kacang Panjang Pada Tekstur Tanah Berpasir. Jurnal Maju, 1(2), 64-82.

[7] Wulandari, F., \& Yuliandri, I. (2014). Diagnosa gangguan gizi menggunakan metode certainty factor. Jurnal Sains dan Teknologi Industri, 11(2), 305-313.

[8] Herawati, S. (2012). Tip \& Trik membuahkan tanaman buah dalam pot. AgroMedia.

[9] Irfan, M. (2013). Respon bawang merah (Allium ascalonicum L) terhadap zat pengatur tumbuh dan unsur hara. Jurnal Agroteknologi, 3(2), 35-40.

[10] Amini, S., \& Syamdidi, S. (2005). Konsentrasi Unsur Hara pada Media dan Pertumbuhan Chlorella vulgaris dengan Pupuk Anorganik Teknis dan Analis. Jurnal Perikanan Universitas Gadjah Mada, 8(2), 201-206.

[11] Fajarditta, F., Sumarsono, S., \& Kusmiyati, F. (2012). Serapan Unsur Hara Nitrogen Dan Phospor Beberapa Tanaman Legum Pada Jenis Tanah Yang Berbeda. Animal Agriculture Journal, 1(2), 41-50.

[12] Syarifudin, A. (2002). Teknik identifikasi mikroorganisme penyedia unsur hara tanaman pada ultisols pulau Buru. Buletin Teknik Pertanian, 1(7), 2124.

[13] Indrasari, A., \& Syukur, A. (2006). Pengaruh pemberian pupuk kandang dan unsur hara mikro terhadap pertumbuhan jagung pada ultisol yang dikapur. Jurnal Ilmu Tanah dan Lingkungan, 6(2), 116-123. 